\title{
Apolipoprotein E genotype and neurodevelopmental sequelae of infant cardiac surgery
}

\author{
J. William Gaynor, MD \\ Marsha Gerdes, $\mathrm{PhD}^{\mathrm{b}}$ \\ Elaine H. Zackai, $M D^{\mathrm{C}}$ \\ Judy Bernbaum, $M D^{d}$ \\ Gil Wernovsky, MD \\ Robert R. Clancy, $\mathrm{MD}^{f}$ \\ Mark F. Newman, $M^{g}$ \\ Ann M. Saunders, $\mathrm{PhD}^{\mathrm{h}}$ \\ Patrick J. Heagerty, $\mathrm{PhD}^{\mathrm{i}}$ \\ Jo Ann D'Agostino, CRNP \\ Donna McDonald-McGinn, MS, CGC ${ }^{\mathrm{C}}$ \\ Susan C. Nicolson, MD \\ Thomas L. Spray, MD \\ Gail P. Jarvik, MD, $P h D^{k}$
}

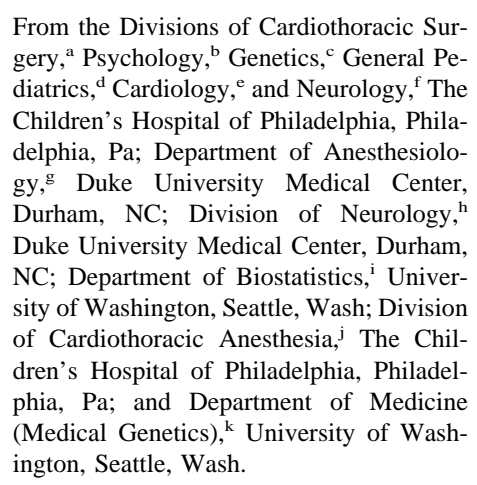
gery, ${ }^{\mathrm{a}}$ Psychology, ${ }^{\mathrm{b}}$ Genetics, ${ }^{\mathrm{c}}$ General Pediatrics, ${ }^{\mathrm{d}}$ Cardiology, ${ }^{\mathrm{e}}$ and Neurology, ${ }^{\mathrm{f}}$ The Children's Hospital of Philadelphia, Philadelphia, Pa; Department of Anesthesiology, ${ }^{\mathrm{g}}$ Duke University Medical Center, Durham, NC; Division of Neurology, Duke University Medical Center, Durham, NC; Department of Biostatistics, ${ }^{\mathrm{i}}$ University of Washington, Seattle, Wash; Division of Cardiothoracic Anesthesia, ${ }^{j}$ The Children's Hospital of Philadelphia, Philadelphia, Pa; and Department of Medicine (Medical Genetics), ${ }^{\mathrm{k}}$ University of Washington, Seattle, Wash.

Supported by an American Heart Association National Grant-In-Aid (9950480N), the Pew Biomedical Scholar Program, and the Fannie E. Rippel Foundation.

Received for publication Nov 25, 2002; revisions requested Feb 10, 2003; revisions received March 7, 2003; accepted for publication April 11, 2003.

Address for reprints: J. William Gaynor, MD, Division of Cardiothoracic Surgery, The Children's Hospital of Philadelphia, 34th and Civic Center Blvd, Ste 8527, Philadelphia, PA 19104 (E-mail: gaynor@ email.chop.edu).

J Thorac Cardiovasc Surg 2003;126: $1736-45$

Copyright $\odot 2003$ by The American Association for Thoracic Surgery

$0022-5223 / 2003 \$ 30.00+0$

doi:10.1067/S0022-5223(03)01188-7
Background: There has been increasing recognition of adverse neurodevelopmental sequelae in some children after repair of congenital heart defects. Even among children with the same cardiac defect, significant interindividual variation exists in developmental outcome. Polymorphisms of apolipoprotein $\mathrm{E}$ have been identified as a risk factor for worse neurologic recovery after central nervous system injury.

Methods: A single-institution prospective study of patients $\leq 6$ months of age undergoing cardiopulmonary bypass for repair of congenital heart defects was undertaken to evaluate the association between apolipoprotein $\mathrm{E}$ genotype and postoperative neurodevelopmental dysfunction. Developmental outcomes were evaluated at 1 year of age by using the Bayley Scales of Infant Development.

Results: One-year evaluation was performed in 244 patients. After adjustment for preoperative and postoperative covariates-including gestational age, age at operation, sex, race, socioeconomic status, cardiac defect, and use of deep hypothermic circulatory arrest-the apolipoprotein E $\epsilon 2$ allele was associated with a worse neurologic outcome as assessed by the Psychomotor Developmental Index of the Bayley Scales of Infant Development $(P=.036)$. Patients with the apolipoprotein E $\epsilon 2$ allele had approximately a 7-point decrease in the Psychomotor Developmental Index.

Conclusions: Apolipoprotein E $\epsilon 2$ allele carriers had significantly lower Psychomotor Development Index scores at 1 year of age after infant cardiac surgery. The effect was independent of ethnicity, socioeconomic status, cardiac defect, and use of deep hypothermic circulatory arrest. An effect of the apolipoprotein $\mathrm{E} \epsilon 4$ allele was not detected. Genetic polymorphisms that decrease neuroresiliency and impair neuronal repair after central nervous system injury are important risk factors for neurodevelopmental dysfunction after infant cardiac surgery. 


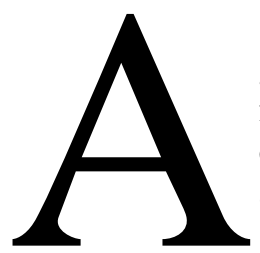

dramatic reduction in mortality after surgical correction of congenital heart defects (CHD) in recent years has been accompanied by increasing recognition of adverse neurodevelopmental sequelae in some survivors. ${ }^{1-3}$ Evaluation of children after neonatal repair of CHD demonstrates a pattern of neurodevelopmental sequelae characterized by cognitive impairment, speech and language abnormalities, impaired visuospatial and visuomotor skills, attention deficit hyperactivity disorder, motor delays, and learning disabilities. ${ }^{4-6}$ Cerebral ischemia in the perioperative period has been proposed to be a primary mechanism of central nervous system (CNS) injury. Management strategies during the operation-including type of support (deep hypothermic circulatory arrest [DHCA] or continuous cardiopulmonary bypass [CPB]), hemodilution, degree of cooling, and blood gas management-have been implicated as factors in postoperative neurodevelopmental dysfunction. ${ }^{1-8}$ These potential risk factors do not fully explain the frequency or pattern of neurodevelopmental dysfunction. There is significant interindividual variation in developmental outcome, even among children with the same cardiac defect, suggesting that other patient-specific factors may be important determinants of CNS injury.

The role of genetic polymorphisms that increase susceptibility to neurologic injury has not been explored in children with CHD. Apolipoprotein E (APOE) is an important regulator of cholesterol metabolism. ${ }^{9-12}$ APOE-containing lipoproteins are the primary lipid transport vehicles in the CNS. There is increasing evidence that APOE is important for neuronal repair. ${ }^{9,11-15}$ There are 3 common isoforms of APOE (E2, E3, and E4), which are encoded by 3 alleles $(\epsilon 2$, $\epsilon 3$, and $\epsilon 4$, respectively) and vary by single amino acid substitutions. A strong association has been validated between the $A P O E \epsilon 4$ allele and Alzheimer's disease. ${ }^{10}$ The $A P O E$ genotype has been shown to have an important role as a determinant of neurologic recovery after CNS ischemia, intracerebral hemorrhage, and traumatic brain injury. ${ }^{13-17}$ There is evidence of an association of APOE genotype with neurocognitive decline after cardiac surgery in adults. ${ }^{18-20}$ We evaluated the association between postoperative neurologic dysfunction and $A P O E$ genotype in infants undergoing cardiac surgery.

\section{Methods}

\section{Patient Population}

The Institutional Review Board at The Children's Hospital of Philadelphia approved the study. Patients 6 months of age or less undergoing $\mathrm{CPB}$, with or without DHCA, for repair of CHD were eligible. Exclusion criteria included (1) multiple congenital anomalies, (2) recognizable genetic or phenotypic syndrome other than chromosome 22q11 microdeletions, and (3) language other than English spoken in the home.
Informed consent was obtained from the parent or guardian. Operations were performed by 4 cardiac surgeons with a dedicated team of cardiac anesthesiologists. Alpha-stat blood gas management was used. DHCA was used at the surgeon's discretion. The mean hematocrit after institution of CPB and hemodilution was $26 \% \pm 3.5 \%$. Before DHCA, patients underwent core cooling with topical hypothermia to a nasopharyngeal temperature of $18^{\circ} \mathrm{C}$. Modified ultrafiltration was performed in all patients.

\section{APOE Genotype Determination}

Whole blood was obtained before the operation and stored at $4{ }^{\circ} \mathrm{C}$. Genomic DNA was prepared and used to determine APOE genotypes by using a previously published method. ${ }^{18,21}$

\section{One-Year Neurodevelopmental Examination}

Children were evaluated at 12 months of age, corrected for prematurity, plus or minus 2 weeks. All study personnel were blinded to the genotype. Socioeconomic status (SES) and ethnicity were determined by parental reporting. Developmental assessment included the Bayley Scales of Infant Development, which yielded 2 scores: the Psychomotor Development Index (PDI) and the Mental Developmental Index (MDI). The MDI assesses memory, problem solving, early number concepts, generalization, vocalizations, and language and social skills. The PDI assesses control of gross muscle function, including crawling and walking, as well as fine muscle skills necessary for prehension, use of writing instruments, and imitation of hand movements. Both the MDI and PDI are normalized to a mean of 100 with an SD of 15 . They yield an accurate assessment of the child's developmental status at 1 year but are not predictors of later outcome, such as IQ in adolescence. The evaluation also included medical history, growth measurements, and detailed neurologic examination assessing active and passive tone, reflexes, gross motor skills, and visual and auditory responses. Patients were evaluated by a genetic dysmorphologist. Because recognition of genetic syndromes in neonates may be difficult, some children with genetic abnormalities had been enrolled as infants. Chromosome analysis and testing for microdeletions of chromosome $22 \mathrm{q} 11$ were performed as indicated.

\section{Data Analysis}

Patients were grouped according to cardiac diagnosis: group 1 consisted of patients with hypoplastic left heart syndrome (HLHS); group 2 consisted of patients with conotruncal defects (tetralogy of Fallot, transposition of the great arteries, truncus arteriosus, and so on); and all other defects were coded as group 3. Patients were additionally coded according to a previously described classification incorporating anatomy and perioperative physiology that has been shown to be predictive of perioperative mortality. ${ }^{22}$ Class I is 2 ventricles with no aortic arch obstruction, class II is 2 ventricles with aortic arch obstruction, class III is single ventricle with no arch obstruction, and class IV is single ventricle with arch obstruction. Patients with tetralogy of Fallot and transposition of the great arteries are in class I, whereas patients with HLHS or variants are in class IV. Results of the genetic evaluations were classified as normal if no genetic or chromosomal abnormality was demonstrated, abnormal if a specific diagnosis was confirmed, and suspect if there was evidence of a genetic syndrome that could not be confirmed. Results of the neurologic examinations were classified 
as normal if no abnormalities or only mild abnormalities that did not affect motor skills were found, suspect when there was a moderate degree of abnormality (ie, moderate hypotonia with generally normal reflexes and mildly abnormal motor skills), and abnormal whenever significant abnormalities of tone, reflexes, or motor skills were present.

\section{Statistical Analysis}

The primary outcome was the PDI, chosen on the basis of the Boston Circulatory Arrest Study finding that use of DHCA was associated with a significant decrease in the PDI. ${ }^{2}$ Secondary measures of neurologic outcome included the MDI, head circumference at 1 year, and neuromuscular examination. The primary predictor of interest was $A P O E$ genotype. Subjects were grouped into the $\epsilon 2$ group $(\epsilon 2 \epsilon 2$ and $\epsilon 3 \epsilon 2)$, the $\epsilon 3 \epsilon 3$ group, and the $\epsilon 4$ group ( $\epsilon 3 \epsilon 4$ and $\epsilon 4 \epsilon 4$ ). There were no $\epsilon 2 \epsilon 2$ patients in the study population. Five $\epsilon 2 \epsilon 4$ subjects were excluded from the analyses because the effects of the $\epsilon 2$ and $\epsilon 4$ alleles are opposing in Alzheimer's disease. Twelve subjects with a missing APOE genotype were also excluded. Because PDI was selected as the primary outcome, we did not make multiple comparison adjustments for analyses of the additional correlated outcomes. Baseline evaluation of $A P O E$ genotype effects used analysis of variance with 2 degrees of freedom $(d f)$, and further investigation of the $A P O E$ effects after covariate adjustment focused on separate comparisons of the $\epsilon 2$ group versus the $\epsilon 3 \epsilon 3$ group and the $\epsilon 4$ group versus the $\epsilon 3 \epsilon 3$ group.

Linear regression was used to characterize the crude and adjusted association between the 1-year outcomes PDI, MDI, and head circumference. Logistic regression was used for the categorical neuromuscular examination outcome. Suspect and abnormal neuromuscular examination groups were pooled to form a "not normal" group and thus derive a binary response variable. Three regressions were performed for each outcome. First, the marginal association between genotype and outcome was considered without adjustment for any covariates. Next, the preoperative adjusted regressions included preoperative characteristics of race (white, black, or other), sex, SES, gestational age, birth weight, head circumference percentiles, diagnostic group, and suspected or definite genetic disorder. Apgar scores were not significantly associated with outcome, and estimates of genotype effect did not substantially change with or without adjustment for Apgar score. Because 11 children were missing Apgar data, Apgar scores were dropped from the regression model rather than imputing the scores or dropping those cases. Missing percentiles of birth weight $(\mathrm{n}=$ $2)$ and head circumferences at birth $(n=24)$ were imputed by using the percentile at the 1-year follow-up examination. Subjects missing birth head circumference measurements were dropped from the analysis of 1-year head circumference. Finally, the preoperative and postoperative adjusted regression included these variables plus variables related to the cardiac repair. Operative variables included class (I-IV), operation, age and weight at operation, hematocrit on CPB, total support time (duration of CPB plus DHCA), number of bypass runs, and use of DHCA. The relationship between $A P O E$ genotype group and all covariates was explored by analysis of variance for quantitative traits and by $\chi^{2}$ analysis for categorical traits.
Interaction between genotype and major preoperative or postoperative covariates was tested by including interaction terms in the preoperative and postoperative adjusted regression analysis. Because the power to detect genotype by covariate interactions was expected to be low, fitted genotype effects for patient subsets were examined to determine whether the same general trends were manifested. Specifically, the signs of coefficients for the $A P O E$ effects were examined in subgroups on the basis of presence of a suspected or definite genetic disorder, males versus females, Caucasian children, SES, diagnostic group, support time, and use of DHCA.

\section{Results}

Between October 1, 1998, and September 20, 2001, 467 eligible patients underwent cardiac surgery (Table 1). Twenty patients died before enrollment. A total of 368 patients $(82 \%)$ were enrolled. Thirteen patients $(3.5 \%)$ died during the initial hospitalization, and 15 additional patients (4.1\%) died after hospital discharge before 1 year of age. There were 340 potential patients for the 1-year evaluation, and $244(72 \%)$ returned. The study population consisted of 244 patients in whom the 1-year evaluation was completed by September 20, 2002. Two additional premature infants born before September 20, 2001, underwent evaluation in October 2002 and are not included in the study population. There was a trend toward a lower return rate among black infants and those with more complex heart defects (class IV). However, the primary reason for not returning was geographic location, because no travel funds were available. There was no difference in $A P O E$ genotype between returning and nonreturning patients.

On the Bayley scales, the mean PDI score was $77.0 \pm$ 18.0, and the mean MDI score was 88.6 \pm 15.5. The MDI was $\leq 70$ in 28 patients $(11 \%)$, and the PDI was $\leq 70$ in 80 patients $(33 \%)$. The neuromuscular examination had abnormal or suspect results in 96 patients (39\%), with hypotonia in 85; hypertonia in 5; mixed tonal abnormalities in 3; and asymmetry, spastic quadriplegia, and hyperreflexia in 1 each. Head circumference at 1 year was at or below the fifth percentile in 60 patients $(25 \%)$. Genetic examination results were normal in 175 patients, a definite genetic abnormality was present in 29 (12\%; including 13 with 22q11 microdeletions), and 40 patients were classified as having suspect results.

No demographic or preoperative characteristics were significantly related to $A P O E$ genotype (Table 2). Although the test for differences of APOE distribution between male and female infants was not significant $(P=.130)$, there was a trend for a deficit of $\epsilon 4$-containing genotypes in males. Allele frequencies in Caucasian males in this sample were $\epsilon 2,0.081$; $\epsilon 3,0.812$; and $\epsilon 4,0.108$; for Caucasian females, they were $\epsilon 2,0.075 ; \epsilon 3,0.769$; and $\epsilon 4,0.157$. Allele frequencies in Caucasian subjects are expected to be 0.085 for $\epsilon 2,0.768$ for $\epsilon 3$, and 0.147 for $\epsilon 4$. The $A P O E$ genotype 
TABLE 1. Characteristics of the patient population

\begin{tabular}{|c|c|c|c|c|c|c|c|c|}
\hline \multirow[b]{2}{*}{ Variable } & \multicolumn{2}{|c|}{$\begin{array}{c}\text { Returned } \\
(\mathrm{n}=244)^{*}\end{array}$} & \multicolumn{2}{|c|}{$\begin{array}{l}\text { Did not return } \\
(\mathbf{n}=94)\end{array}$} & \multicolumn{2}{|c|}{$\begin{array}{l}\text { Hospital death } \\
\quad(n=13)\end{array}$} & \multicolumn{2}{|c|}{$\begin{array}{l}\text { Late death } \\
(\mathrm{n}=15)\end{array}$} \\
\hline & No. & $\%$ & No. & $\%$ & No. & $\%$ & No. & $\%$ \\
\hline \multicolumn{9}{|l|}{ Race } \\
\hline $\begin{array}{l}\text { Asian/Pacific Islander, Hispanic, } \\
\text { Native American, other }\end{array}$ & 42 & 17 & 21 & 22 & 4 & 31 & 1 & 7 \\
\hline Black, not Hispanic & 31 & 13 & 29 & 31 & 3 & 23 & 3 & 20 \\
\hline White, not hispanic & 171 & 70 & 44 & 47 & 6 & 46 & 11 & 73 \\
\hline \multicolumn{9}{|l|}{ Sex } \\
\hline Female & 145 & 59 & 58 & 62 & 8 & 62 & 8 & 53 \\
\hline Male & 99 & 41 & 36 & 38 & 5 & 38 & 7 & 47 \\
\hline \multicolumn{9}{|l|}{$A P O E$ genotype } \\
\hline$\epsilon 2 \epsilon 2$ & 0 & & 2 & 2.1 & 0 & & 0 & \\
\hline$\epsilon 2 \epsilon 3$ & 28 & 11.5 & 11 & 11.7 & 2 & 15.4 & 1 & 6.7 \\
\hline$\epsilon 2 \epsilon 4$ & 5 & 2.0 & 4 & 4.3 & 1 & 7.6 & 0 & \\
\hline$\epsilon 3 \epsilon 3$ & 147 & 60.2 & 53 & 56.4 & 6 & 46.2 & 8 & 53.3 \\
\hline$\epsilon 3 \epsilon 4$ & 48 & 19.7 & 16 & 17.0 & 2 & 15.4 & 4 & 46.7 \\
\hline$\epsilon 4 \epsilon 4$ & 4 & 1.7 & 1 & 1.1 & 0 & & 0 & \\
\hline Not done & 12 & 4.9 & 7 & 7.4 & 2 & 15.4 & 2 & 13.3 \\
\hline \multicolumn{9}{|l|}{ Gestational age (wk) } \\
\hline Mean $\pm S D$ & \multirow{2}{*}{\multicolumn{2}{|c|}{$\begin{array}{l}38.5 \pm 2.1 \\
\quad 242\end{array}$}} & \multirow{2}{*}{\multicolumn{2}{|c|}{$\begin{array}{l}38.5 \pm 1.8 \\
80\end{array}$}} & \multirow{2}{*}{\multicolumn{2}{|c|}{$36.8 \pm 2.6$}} & \multirow{2}{*}{\multicolumn{2}{|c|}{$37.1 \pm 4.4$}} \\
\hline $\mathrm{n}$ & & & & & & & & \\
\hline \multicolumn{9}{|l|}{ Birth weight $(\mathrm{g})$} \\
\hline Mean $\pm S D$ & \multirow{2}{*}{\multicolumn{2}{|c|}{$\begin{array}{l}3172 \pm 634 \\
243\end{array}$}} & \multirow{2}{*}{\multicolumn{2}{|c|}{$\begin{array}{l}3124 \pm 573 \\
83\end{array}$}} & \multirow{2}{*}{\multicolumn{2}{|c|}{$2752 \pm 459$}} & \multicolumn{2}{|c|}{$2680 \pm 793$} \\
\hline $\mathrm{n}$ & & & & & & & & \\
\hline \multicolumn{9}{|l|}{ Birth head circumference $(\%)$} \\
\hline Mean $\pm S D$ & \multirow{2}{*}{\multicolumn{2}{|c|}{$\begin{array}{c}43 \pm 31 \\
231\end{array}$}} & \multirow{2}{*}{\multicolumn{2}{|c|}{$38 \pm 29$}} & \multirow{2}{*}{\multicolumn{2}{|c|}{$37 \pm \frac{31}{7}$}} & & \\
\hline $\mathrm{n}$ & & & & & & & & \\
\hline Apgar at $1 \mathrm{~min}$ & & & & & & & & \\
\hline Mean \pm SD & & & & & & & & \\
\hline $\mathrm{n}$ & & & & & & & & \\
\hline Apgar at $5 \mathrm{~min}$ & & & & & & & & \\
\hline Mean \pm SD & & & & & & & & \\
\hline $\mathrm{n}$ & & & & & & & & \\
\hline Diagnostic group & & & & & & & & \\
\hline HLHS & 35 & 14.3 & 18 & 19.1 & 6 & 46.2 & 7 & 46.6 \\
\hline Conotruncal defects & 135 & 55.3 & 54 & 57.4 & 2 & 15.4 & 4 & 26.7 \\
\hline Other defects & 74 & 30.4 & 22 & 23.5 & 5 & 35.4 & 4 & 26.7 \\
\hline Operative class & & & & & & & & \\
\hline Two ventricles: no arch obstruction & 143 & 58.6 & 43 & 45.7 & 3 & 23.1 & 3 & 20.0 \\
\hline Two ventricles: arch obstruction & 21 & 8.6 & 14 & 14.9 & 1 & 7.7 & 1 & 6.7 \\
\hline Single ventricle: no arch obstruction & 29 & 11.9 & 5 & 5.3 & 1 & 7.7 & 3 & 20.0 \\
\hline Single ventricle: arch obstruction & 51 & 20.9 & 32 & 34.1 & 8 & 61.5 & 8 & 53.3 \\
\hline Age at first operation (d) & & & & & & & & \\
\hline Mean $\pm S D$ & & & & & & & & \\
\hline Median (range) & & & & & & & & \\
\hline Weight at first operation, $\mathrm{kg}$ (mean $\pm \mathrm{SD}$ ) & & 32 & & 26 & & 93 & & 02 \\
\hline
\end{tabular}

*Two premature infants born before September 20, 2001, were scheduled for evaluation in 0ctober 2002.

distribution did not significantly differ from Hardy-Weinberg proportions. ${ }^{21}$ APOE genotype frequencies are expected to vary by race. ${ }^{22-25}$ Although this variation was not statistically significant, the expected deficit of $\epsilon 4$ alleles in Asians was seen. The distribution of male and female subjects did not differ significantly by race $(P=.17$; data not shown). Operative variables for the first operation and for the entire first year of life are shown in Tables 3 and 4, respectively. None was related to $A P O E$ genotype (all $P>$ .2).

The neurologic outcomes, stratified by $A P O E$ genotype, are shown in Table 5 and are shown for the Caucasian subgroup in Table 6. All other analyses use all races. Regression analyses unadjusted for any covariates showed a significant APOE effect for PDI $(P=.016 ; 2 d f)$ and neuromuscular examination $(P=.032 ; 2 d f$; Figure 1$)$. In 
TABLE 2. Preoperative variables stratified by APOE genotype

\begin{tabular}{|c|c|c|c|c|c|c|c|c|c|c|c|}
\hline \multirow[b]{2}{*}{ Variable } & \multicolumn{2}{|c|}{$\begin{array}{c}\text { Missing APOE } \\
\text { and } \epsilon 2 \epsilon 4 \\
\end{array}$} & \multicolumn{2}{|c|}{$\epsilon 2 \epsilon 2, \epsilon 2 \epsilon 3$} & \multicolumn{2}{|c|}{$\epsilon 3 \epsilon 3$} & \multicolumn{2}{|c|}{$\epsilon 3 \in 4, \epsilon 4 \in 4$} & \multicolumn{2}{|c|}{ All } & \multirow[b]{2}{*}{$P$ value* } \\
\hline & No. & $\%$ & No. & $\%$ & No. & $\%$ & No. & $\%$ & No. & $\%$ & \\
\hline \multicolumn{12}{|l|}{ Race } \\
\hline $\begin{array}{l}\text { Asian/Pacific Islander, } \\
\text { Hispanic, Native } \\
\text { American, other }\end{array}$ & 2 & 11.7 & 3 & 10.7 & 31 & 21.1 & 7 & 13.5 & 43 & 17.6 & \multirow[t]{3}{*}{.308} \\
\hline Black, not hispanic & 5 & 29.4 & 3 & 10.7 & 16 & 10.9 & 10 & 19.2 & 34 & 13.9 & \\
\hline White, not hispanic & 10 & 58.9 & 22 & 78.6 & 100 & 68.0 & 35 & 67.3 & 167 & 68.5 & \\
\hline \multicolumn{12}{|l|}{ Sex } \\
\hline Female & 8 & 47.1 & 10 & 35.7 & 57 & 38.8 & 28 & 53.8 & 103 & 42.2 & \multirow[t]{2}{*}{.130} \\
\hline Male & 9 & 52.9 & 18 & 64.3 & 90 & 61.2 & 24 & 46.2 & 141 & 57.8 & \\
\hline \multicolumn{12}{|l|}{ SES } \\
\hline Groups 1 through 3 & 4 & 23.5 & 13 & 46.4 & 41 & 28.1 & 19 & 36.5 & 77 & 31.7 & \multirow[t]{2}{*}{.124} \\
\hline Groups 4 and 5 & 13 & 76.5 & 15 & 53.6 & 105 & 71.9 & 33 & 63.5 & 166 & 68.3 & \\
\hline \multicolumn{12}{|l|}{ Genetic exclusion } \\
\hline Normal & 10 & 58.9 & 19 & 67.9 & 110 & 74.8 & 36 & 69.2 & 175 & 71.7 & \multirow[t]{3}{*}{.759} \\
\hline Abnormal & 2 & 11.7 & 5 & 17.9 & 16 & 10.9 & 6 & 11.6 & 29 & 11.9 & \\
\hline Unknown & 5 & 29.4 & 4 & 14.2 & 21 & 14.3 & 10 & 19.2 & 40 & 16.4 & \\
\hline \multicolumn{12}{|l|}{ Gestational age (wk) } \\
\hline Mean \pm SD & \multirow{2}{*}{\multicolumn{2}{|c|}{$38.3 \pm 2.3$}} & \multirow{2}{*}{\multicolumn{2}{|c|}{$\begin{array}{l}38.5 \pm 2.8 \\
28\end{array}$}} & \multirow{2}{*}{\multicolumn{2}{|c|}{$\begin{array}{l}38.4 \pm 2.1 \\
147\end{array}$}} & \multirow{2}{*}{\multicolumn{2}{|c|}{$\begin{array}{l}39.1 \pm 1.8 \\
52\end{array}$}} & \multirow{2}{*}{\multicolumn{2}{|c|}{$\begin{array}{c}38.6^{*} \pm 2.1 \\
244\end{array}$}} & \multirow[t]{2}{*}{.151} \\
\hline $\mathrm{n}$ & & & & & & & & & & & \\
\hline \multicolumn{12}{|l|}{ Birth weight $(\%)$} \\
\hline $\begin{array}{l}\text { Mean } \pm S D \\
n\end{array}$ & \multirow{2}{*}{\multicolumn{2}{|c|}{$48.8 \pm 31.0$}} & \multirow{2}{*}{\multicolumn{2}{|c|}{$55.5 \pm 31.9$}} & \multirow{2}{*}{\multicolumn{2}{|c|}{$\begin{array}{c}49.2 \pm 29.5 \\
147\end{array}$}} & \multicolumn{2}{|c|}{$59.4 \pm 29.4$} & \multicolumn{2}{|c|}{$\begin{array}{c}52 .{ }^{*} 3 \pm 30.0 \\
243\end{array}$} & .091 \\
\hline \multicolumn{7}{|c|}{ Birth head circumference $(\%)$} & & & & & \\
\hline $\begin{array}{l}\text { Mean } \pm S D \\
n\end{array}$ & \multicolumn{2}{|c|}{$45.7 \pm 30.0$} & 43.1 & 34.9 & 41.6 & 30.9 & 43.6 & 29.7 & $42.2^{*}$ & 31.0 & .920 \\
\hline Apgar at $1 \mathrm{~min}$ & & & & & & & & & & & \\
\hline $\mathrm{Mean}_{\mathrm{n}} \pm \mathrm{SD}$ & & & & 1.6 & & 1.7 & & & $7.7^{*}$ & 1.6 & .665 \\
\hline Apgar at $5 \mathrm{~min}$ & & & & & & & & & & & \\
\hline $\mathrm{M}_{\mathrm{n}} \mathrm{Mean} \pm \mathrm{SD}$ & & & & 1.0 & & 1.0 & & & $8.6^{*}$ & 0.9 & .319 \\
\hline
\end{tabular}

*Does not include $\epsilon 2 \epsilon 4$ and missing genotypes.

each case, infants in the APOE $\epsilon 2$ group performed less well than those with the reference $\epsilon 3 \epsilon 3$ genotype. Comparing the $\epsilon 2$ group with the other groups pooled gave $P$ values of $.006, .041, .041$, and .27 for PDI, MDI, neuromuscular examination, and head circumference, respectively (Table 7).

The APOE $\epsilon 2$ effect on PDI remained significant after adjusting for the preoperative $(P=.023)$ or preoperative and postoperative $(P=.036)$ covariates (Table 7). After adjustment for covariates, the APOE $\epsilon 2$ group had an approximately 7-point decrease in PDI score. The smaller $\epsilon 2$ effect on MDI was not significant after preoperative $(P=$ $.09)$ or preoperative plus postoperative $(P=.13)$ covariate adjustment, although the trend of poorer outcome among the $\epsilon 2$ subjects persisted. The effect of APOE $\epsilon 2$ on neuromuscular examination was no longer significant after preoperative $(P=.18)$ or preoperative plus postoperative $(P=$ .26) covariate adjustment. Head circumference at 1 year did not have a significant $A P O E$ genotype effect with or without covariate adjustment.
An $A P O E \in 4$ effect was not seen for any outcome. The regression coefficients for the covariate-adjusted regression were near 0 for PDI and MDI. After covariate adjustment, nonsignificantly negative coefficients were seen for the $\epsilon 4$ effect on PDI, MDI, and head circumference.

There was no statistically significant interaction between the pooled $A P O E \epsilon 2$ group and presence of a genetic syndrome, sex, race, SES, diagnostic group, operative class, support time, or use of DHCA in the analysis of PDI or MDI. Power to detect interactions was expected to be low in this sample size; therefore, the estimated APOE coefficients specific to covariate strata were examined for consistency. For prediction of PDI, the coefficients of the pooled group compared with the $\epsilon 3 \epsilon 3$ reference group were negative for all strata evaluated, except for diagnostic group 1 (HLHS; 1.2; SD, 7.3) and Hispanic race (13.1; SD, 17.0). The effect of the $\epsilon 2$ group on PDI was -4.1 (SD, 3.9) in subjects with normal genetic evaluation results and $-6.9(\mathrm{SD}, 8.0)$ in subjects who were thought to have a genetic disorder. The $\epsilon 2$ coefficient for PDI was -1.7 (SD, 5.3) in females and 
TABLE 3. Perioperative variables stratified by $A P O E$ genotype: first operation

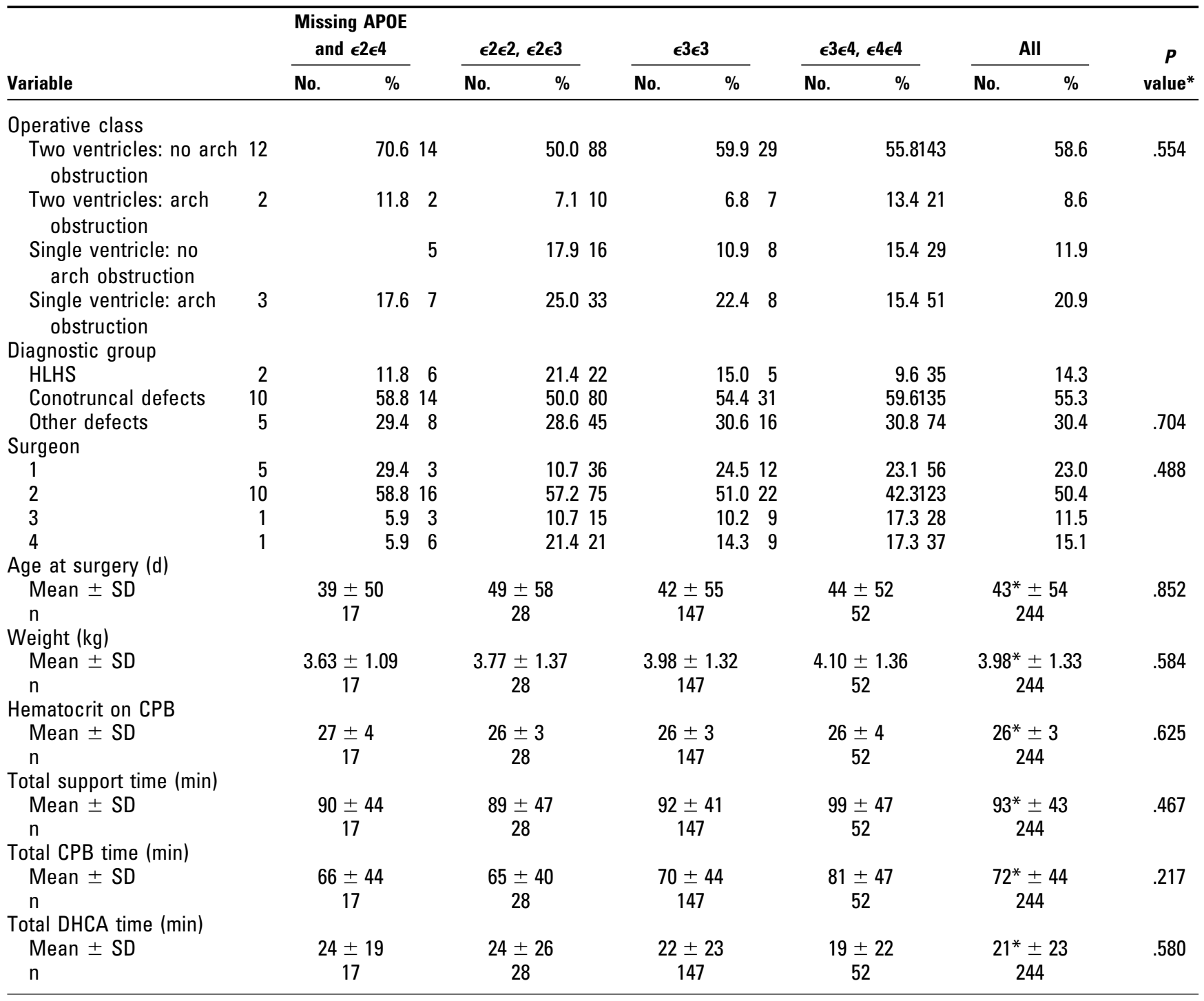

*Does not include $\epsilon 2 \epsilon 4$ and missing genotypes.

-10.4 (SD, 4.2) in males. The $\epsilon 2$ coefficient for MDI analysis was negative in all strata except diagnostic group 1 (HLHS; 3.2; SD, 6.6) and class IV patients (1.7; SD, 6.0).

For the analysis of PDI and MDI, there was no significant interaction between the $A P O E \epsilon 3 \epsilon 4$ and $\epsilon 4 \epsilon 4$ genotype groups and presence of a genetic syndrome, sex, race, SES, diagnostic group, operative class, or DHCA. For neuromuscular examination, the $\epsilon 2$ group generally had worse examination results across the strata evaluated. A marginally significant $A P O E$ genotype $\times$ sex interaction $(P=.0581)$ was detected in the analysis of neurologic examination. Only the $\epsilon 2$ group males had worse examination results than the $\epsilon 3 \epsilon 3$ genotype group $(-1.8 ; \mathrm{SD}, 0.8)$; the $\epsilon 2$ group coefficient for females was 1.0 (SD, 0.9).

For the prediction of head circumference, a marginal $A P O E$ genotype $\times$ genetic diagnosis interaction was de- tected $(P=.0503)$. The coefficient for the $\epsilon 2$ group without evidence of a genetic disorder was -7.4 (7.2), whereas that for the $\epsilon 2$ group with evidence of a genetic disorder was 20.0 (SD, 14.3). The $\epsilon 4$ coefficients without and with evidence of a genetic disorder were 0.05 (SD, 5.5) and 22.9 (SD, 13.6), respectively.

\section{Discussion}

There is a significant effect of the APOE $\epsilon 2$ allele to predict lower PDI at 1 year of age after infant cardiac surgery; this is independent of race, SES, cardiac defect, and use of DHCA. This finding is consistent with the hypothesis that $A P O E$ genotypes other than the common $\epsilon 3 \epsilon 3$ predict decreased neuroresiliency after CNS injury. An APOE $\in 4$ effect is not detectable. 
TABLE 4. Operative data: first year of life

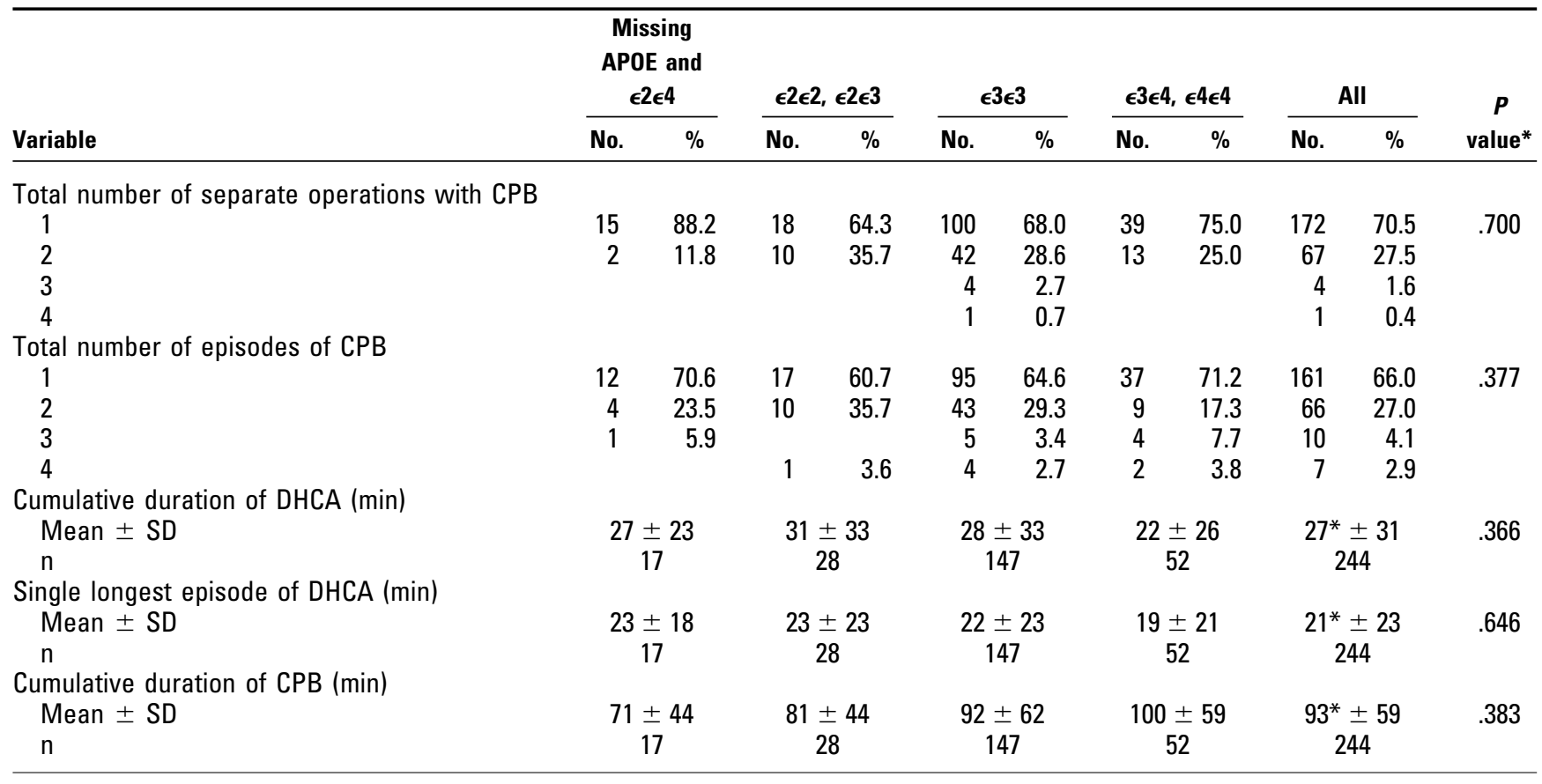

*Does not include $\epsilon 2 \epsilon 4$ and missing genotypes.

TABLE 5. Neurodevelopmental outcomes at 1 year stratified by APOE genotype

\begin{tabular}{|c|c|c|c|c|c|c|c|c|c|}
\hline \multirow[b]{2}{*}{ Variable } & \multicolumn{2}{|c|}{$\epsilon 2 \epsilon 2, \epsilon 2 \epsilon 3$} & \multicolumn{2}{|c|}{$\epsilon 3 \epsilon 3$} & \multicolumn{2}{|c|}{$\epsilon 3 \epsilon 4, \epsilon 4 \epsilon 4$} & \multicolumn{2}{|c|}{ All } & \multirow{2}{*}{$\begin{array}{c}P \\
\text { value* }\end{array}$} \\
\hline & No. & $\%$ & No. & $\%$ & No. & $\%$ & No. & $\%$ & \\
\hline \multicolumn{10}{|c|}{ Psychomotor Developmental Index } \\
\hline Mean \pm SD & \multicolumn{2}{|c|}{$67.89 \pm \frac{18.28}{28}$} & \multicolumn{2}{|c|}{$\begin{array}{c}77.86 \pm 17.74 \\
147\end{array}$} & \multicolumn{2}{|c|}{$78.17 \pm 15.04$} & \multicolumn{2}{|c|}{$\begin{array}{c}76.70^{*} \pm 17.47 \\
244\end{array}$} & .016 \\
\hline \multicolumn{10}{|c|}{ Mental Developmental Index } \\
\hline $\begin{array}{l}\text { Mean } \pm S D \\
n\end{array}$ & \multicolumn{2}{|c|}{$83.32 \pm 17.43$} & \multicolumn{2}{|c|}{$\begin{array}{c}89.65 \pm 14.66 \\
147\end{array}$} & \multicolumn{2}{|c|}{$89.58 \pm 14.09$} & \multicolumn{2}{|c|}{$\begin{array}{c}88.85^{*} \pm 14.97 \\
244\end{array}$} & .144 \\
\hline \multicolumn{10}{|c|}{ Results of neuromuscular examination } \\
\hline Normal & 11 & 39.3 & 89 & 60.5 & 36 & 69.2 & 148 & 60.7 & .032 \\
\hline Abnormal or suspect & 17 & 60.7 & 58 & 39.5 & 16 & 30.8 & 96 & 39.3 & \\
\hline \multicolumn{10}{|c|}{ Head circumference at testing $(\%)$} \\
\hline$\underset{n}{\text { Mean } \pm S D}$ & \multicolumn{2}{|c|}{$29.93 \pm 26.63$} & \multicolumn{2}{|c|}{$\begin{array}{c}36.81 \pm 30.83 \\
146\end{array}$} & \multicolumn{2}{|c|}{$\begin{array}{c}38.80 \pm 28.69 \\
52\end{array}$} & \multicolumn{2}{|c|}{$\begin{array}{c}36.41^{*} \pm 29.85 \\
243\end{array}$} & .434 \\
\hline
\end{tabular}

*Does not include $\epsilon 2 \epsilon 4$ and missing genotypes.

The gene for the human APOE is located on the long arm of chromosome 19 and codes for a 299-amino acid protein. ${ }^{11}$ The most common allele in humans is $\epsilon 3$, and there are 2 other common alleles, $\epsilon 2$ and $\epsilon 4$, whose protein products differ from that of $\epsilon 3$ by single amino acid substitutions. There are 3 homozygous genotypes $(\epsilon 2 \epsilon 2, \epsilon 3 \epsilon 3$, and $\epsilon 4 \epsilon 4)$ and 3 heterozygous genotypes $(\epsilon 2 \epsilon 3, \epsilon 2 \epsilon 4$, and $\epsilon 3 \epsilon 4)$. Allele frequency varies according to ethnic background. ${ }^{21-27}$

The APOE protein is the receptor ligand for low-density lipoprotein cholesterol. APOE-containing lipoproteins are the primary lipid transport vehicles in the CNS. APOE modulates lipoprotein levels by effects on clearance rate, lipolytic conversion, and very-low-density lipoprotein (VLDL) triglyceride production. ${ }^{11}$ In addition, APOE has an important role in mobilization and redistribution of cholesterol and phospholipids during remodeling of neuronal membranes. The normal function of APOE within neurons is thought to be maintenance of microtubular integrity and stabilization of the neuronal cytoskeleton. ${ }^{11}$ APOE synthesis is upregulated by astrocytes and oligodendrocytes after CNS injury or cerebral ischemia. After an injury, APOE immunoreactivity increases first in astrocytes and later in neurons. The temporal changes in localization and levels of 


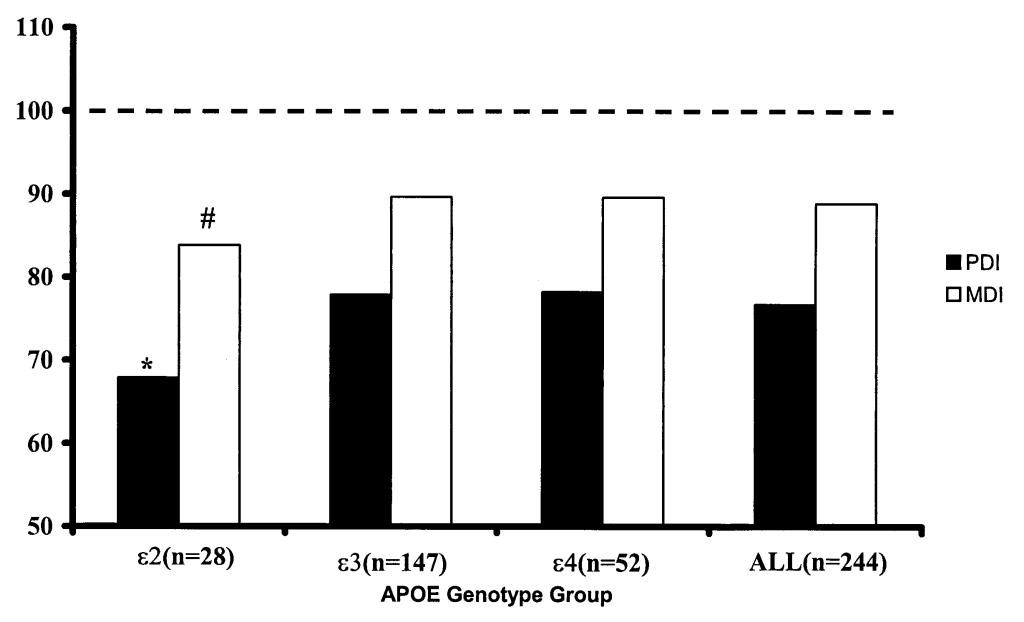

Figure 1. Mental Developmental Index (MDI) and Psychomotor Development Index (PDI) stratified by apolipoprotein $E(A P O E)$ genotype. ${ }^{*} P=.006$ versus other groups pooled, unadjusted for covariates. $\# P=.041$ versus other groups pooled, unadjusted for covariates. The dashed line represents the expected population mean.

TABLE 6. Outcomes for the white subgroup

\begin{tabular}{|c|c|c|c|c|c|c|c|c|c|}
\hline \multirow[b]{2}{*}{ Variable } & \multicolumn{2}{|c|}{$\epsilon 2 \epsilon 2, \epsilon 2 \epsilon 3$} & \multicolumn{2}{|c|}{$\epsilon 3 \epsilon 3$} & \multicolumn{2}{|c|}{$\epsilon 3 \in 4, \epsilon 4 \epsilon 4$} & \multicolumn{2}{|c|}{ All } & \multirow{2}{*}{$\begin{array}{c}P \\
\text { value* }\end{array}$} \\
\hline & No. & $\%$ & No. & $\%$ & No. & $\%$ & No. & $\%$ & \\
\hline \multicolumn{10}{|c|}{ Psychomotor Developmental Index } \\
\hline $\begin{array}{l}\text { Mean } \pm S D \\
n\end{array}$ & \multicolumn{2}{|c|}{$65.91 \pm 19.13$} & \multicolumn{2}{|c|}{$\begin{array}{c}75.31 \pm 16.89 \\
100\end{array}$} & \multicolumn{2}{|c|}{$\begin{array}{c}75.89 \pm 14.21 \\
35\end{array}$} & \multicolumn{2}{|c|}{$\begin{array}{c}74.12^{*} \pm 16.89 \\
167\end{array}$} & .047 \\
\hline \multicolumn{10}{|c|}{ Mental Developmental Index } \\
\hline $\begin{array}{l}\text { Mean } \pm S D \\
\text { SD }\end{array}$ & \multicolumn{2}{|c|}{$\begin{array}{c}82.45 \pm 18.96 \\
22\end{array}$} & \multicolumn{2}{|c|}{$\begin{array}{c}90.31 \pm 14.75 \\
100\end{array}$} & \multicolumn{2}{|c|}{$88.91 \pm 15.85$} & \multicolumn{2}{|c|}{$\begin{array}{c}88.90^{*} \pm 15.76 \\
167\end{array}$} & .149 \\
\hline \multicolumn{10}{|c|}{ Results of neuromuscular examination } \\
\hline Normal & 7 & 31.8 & 55 & 55.0 & 22 & 62.9 & 91 & 54.5 & .065 \\
\hline Not normal & 15 & 68.2 & 45 & 45.0 & 13 & 37.1 & 76 & 45.5 & \\
\hline \multicolumn{10}{|c|}{ Head circumference at testing $(\%)$} \\
\hline $\begin{array}{l}\text { Mean } \pm S D \\
n\end{array}$ & \multicolumn{2}{|c|}{$\begin{array}{c}27.89 \pm 26.68 \\
22\end{array}$} & \multicolumn{2}{|c|}{$\begin{array}{c}40.54 \pm 32.11 \\
99\end{array}$} & \multicolumn{2}{|c|}{$38.80 \pm 28.43$} & \multicolumn{2}{|c|}{$\begin{array}{c}38.37^{*} \pm 30.73 \\
166\end{array}$} & .217 \\
\hline
\end{tabular}

*Does not include $\epsilon 2 \epsilon 4$ and missing genotypes.

APOE are consistent with an upregulation of APOE by astrocytes in response to injury, release into the extracellular space, and uptake by neurons. APOE immunoreactivity after global ischemia is localized to vulnerable regions such as the caudate and CA1 region of the hippocampus. Studies in $A P O E$ knockout mice have shown that APOE deficiency worsens neuronal injury after cerebral ischemia and compromises the blood-brain barrier after CNS injury., ${ }^{9,11,28}$ Mechanisms by which APOE may modify CNS injury include protection against oxidative stress, modulation of the glial response to inflammation, and a direct neurotropic effect on injured neurons. ${ }^{7,9,29,30}$

Infants undergoing cardiac surgery are at risk for CNS injury and adverse neurodevelopmental sequelae that significantly diminish the quality of life for these children and their parents. ${ }^{1-6}$ The need for early intervention, special education, and rehabilitative services results in considerable cost to society. Significant interindividual variation in outcome exists that cannot be completely explained by previously reported risk factors. ${ }^{3,5,6}$ Recent studies suggest that $A P O E \in 4$ may be a risk factor for neurocognitive decline after heart surgery in adults; however, the evidence is not conclusive. ${ }^{18-20}$ The mechanisms of CNS injury during infant cardiac surgery are poorly understood and are likely different from those in adults. ${ }^{7}$ Children with CHD often have congenital CNS anomalies; in addition, many are hypoxic before and after surgery. Use of DHCA results in a period of global cerebral ischemia. Mechanisms of CNS injury in infants undergoing cardiac surgery include hypoxia/ischemia, emboli, reactive oxygen species, and inflammatory microvasculopathy. ${ }^{7} A P O E$ genotype has been shown to modify the inflammatory 
TABLE 7. Logistic regression coefficients for APOE genotype group effects

\begin{tabular}{|c|c|c|c|c|}
\hline Variable & APOE & Unadjusted & $\begin{array}{l}\text { Preoperative adjusted } \\
\text { regression }\end{array}$ & $\begin{array}{c}\text { Preoperative and } \\
\text { postoperative adjusted } \\
\text { regression }\end{array}$ \\
\hline PDI & $\begin{array}{l}\epsilon 2 \\
\epsilon 4\end{array}$ & $\begin{aligned}-9.971(3.553), P & =.006^{*} \\
0.309(2.780), P & =.91\end{aligned}$ & $\begin{array}{l}-7.221(3.150), P=.023^{*} \\
-0.569(2.743), P=.82\end{array}$ & $\begin{array}{l}-6.979(3.305), P=.036^{*} \\
-0.362(2.601), P=.89\end{array}$ \\
\hline MDI & $\begin{array}{l}\epsilon 2 \\
\epsilon 4\end{array}$ & $\begin{array}{l}-6.325(3.071), P=.041^{*} \\
-0.069(2.403), P=.98\end{array}$ & $\begin{array}{l}-4.893(2.866), P=.089 \\
-0.899(2.300), P=.70\end{array}$ & $\begin{array}{l}-4.661(3.047), P=.128 \\
-1.094(2.403), P=.65\end{array}$ \\
\hline Head circumference & $\begin{array}{l}\epsilon 2 \\
\epsilon 4\end{array}$ & $\begin{array}{r}-6.880(6.162), P=.27 \\
1.990(4.823), P=.68\end{array}$ & $\begin{array}{l}-8.206(5.880), P=.16 \\
-0.951(4.986), P=.84\end{array}$ & $\begin{array}{l}-6.580(6.215), P=.29 \\
-1.086(4.890), P=.83\end{array}$ \\
\hline Neuromuscular examination results $\dagger$ & $\begin{array}{l}\epsilon 2 \\
\epsilon 4\end{array}$ & $\begin{aligned}-0.864(0.422), P & =.041 \\
0.382(0.343), P & =.26\end{aligned}$ & $\begin{array}{r}-0.675(0.508), P=.184 \\
0.580(0.428), P=.176\end{array}$ & $\begin{aligned}-0.605(0.540), P & =.26 \\
0.722(0.455), P & =.113\end{aligned}$ \\
\hline
\end{tabular}

The coefficients are relative to the common $\epsilon 3 \epsilon 3$ genotype group. The SDs are given in parentheses.

${ }^{*} P<.05$.

$\dagger(0$, Suspect or abnormal; 1, normal; coefficients are the log odds ratios).

response to $\mathrm{CPB}$ and is a risk factor for postoperative renal dysfunction. ${ }^{29,31,32}$

Previous studies have implicated $A P O E \in 4$ as a risk factor for recovery after brain injury and for Alzheimer's disease. ${ }^{9-13}$ Few studies have focused on the $\epsilon 2$ allele; most classified patients as $\epsilon 4$ positive or $\epsilon 4$ negative and did not assess the $\epsilon 2$ allele because of its rarity. APOE $\epsilon 2$ has been shown to adversely influence recovery after ischemic stroke and cardiac arrest and to increase the risk of intracerebral hemorrhage. ${ }^{12,14-17}$ The frequency of all 3 APOE alleles suggests some balancing selection; certain alleles are better under some conditions, and other alleles are better under other conditions.

Although this study provides strong evidence of an adverse effect of the $A P O E \epsilon 2$ allele on neurodevelopmental outcome, there are several limitations. Children with CHD are heterogeneous, and many factors besides the genetic profile affect outcome. However, the sequential analysis performed in this study adjusted for both patient and procedural factors known to affect outcome. Furthermore, no interaction of $A P O E$ genotype with these factors could be identified. In addition, the $A P O E \epsilon 2$ allele is rare, and the possibility that the $A P O E$ genotype is a surrogate for some unidentified factor cannot be excluded. There is evidence that the APOE alleles are heterogeneous within themselves, and some variants may be more strongly related to outcome than others. Full sequencing of the APOE region of 72 African American and European individuals detected many single nucleotide polymorphisms. These studies suggest that there is a substructure within the common $\epsilon 2, \epsilon 3$, and $\epsilon 4$ alleles. ${ }^{33}$ In other words, each of these alleles is heterogeneous, although primarily in the noncoding regions. Although it is possible that an unidentified subset of the $\epsilon 2$ alleles is associated with poor outcome, rather than the entire $\epsilon 2$ group, a direct effect of the coding change is the most likely cause of an association. The lack of any trend toward a performance difference among carriers of the $\epsilon 4$ allele suggests that a true $\epsilon 4$ effect was not missed. Finally, neurodevelopmental assessment at 1 year of age is not predictive of long-term outcome. Only further evaluation of these children at an older age can determine whether $A P O E$ genotype is a risk factor for worse long-term outcome.

In summary, the $A P O E \epsilon 2$ allele predicts worse neurodevelopmental outcome at 1 year of age after infant repair of CHD. This APOE genotype-environment interaction demonstrates that genetic polymorphisms that impair neuroresiliency and CNS recovery may explain some of the interindividual variation in developmental outcome after surgery for CHD. Further studies, with more reliable and thorough testing, are necessary as the children reach school age to determine whether APOE genotype predicts a worse long-term neurodevelopmental outcome.

We acknowledge the contributions of the many physicians, nurses, and other personnel who aided in the care of these patients and the conduct of the study, including Ann M. Jenkins, Susan Poulton, William M. DeCampli, MD, Tom R. Karl, MD, Lisa M. Montenegro, MD, Nancy B. Burnham, Diane M. Hartman, Shannon Hittle, and Suzanne Gribbin.

\section{References}

1. Newburger JW, Jonas RA, Wernovsky G, Wypij D, Hickey PR, Kuban $\mathrm{KCK}$, et al. A comparison of the perioperative neurologic effects of hypothermic circulatory arrest versus low-flow cardiopulmonary bypass in infant heart surgery. $N$ Engl J Med. 1993;329:1057-64.

2. Bellinger DC, Jonas RA, Rappaport LA, Wypij D, Wernovsky G, Kuban KCK, et al. Developmental and neurologic status of children after heart surgery with hypothermic circulatory arrest or low-flow cardiopulmonary bypass. N Engl J Med. 1995;332:549-55.

3. Bellinger DC, Wypij D, Kuban KCK, Rappaport LA, Hickey PR, Wernovsky G, et al. Developmental and neurological status of children at 4 years of age after heart surgery with hypothermic circulatory arrest or low-flow cardiopulmonary bypass. Circulation. 1999;100:526-32.

4. Wernovsky G, Stiles KM, Gauvreau K, Gentles TL, du Plessis AJ, Bellinger DC, et al. Cognitive development after the Fontan operation. Circulation. 2000;102:883-9. 
5. Mahle MT, Wernovsky G, Moss EM, Gerdes M, Jobes DA, Clancy RR. Neurodevelopmental outcome and lifestyle assessment in school age and adolescent children with hypoplastic left heart syndrome. Pediatrics. 2000;105:1082-9.

6. Bellinger DC, Wypij D, du Plessis AJ, Rappaport LA, Wernovsky G, Jonas RA, et al. Eight-year neurodevelopmental status. The Boston circulatory arrest study. Circulation. 2000;102:II-497.

7. du Plessis AJ. Mechanisms of brain injury during cardiac surgery. Semin Pediatr Neurol. 1999;6:32-47.

8. Bellinger DC, Wypij D, du Plessis AJ, Rappaport LA, Riviello J, Jonas RA, et al. Developmental and neurologic effects of alpha-stat versus $\mathrm{pH}$-stat strategies for deep hypothermic cardiopulmonary bypass in infants. J Thorac Cardiovasc Surg. 2001;121:374-83.

9. Strittmatter WJ, Bova Hill C. Molecular biology of apolipoprotein E. Curr Opin Lipidol. 2002;13:119-23.

10. Jarvik GP. Genetic predictors of common disease: apolipoprotein $\mathrm{E}$ genotype as a paradigm. Ann Epidemiol. 1997;7:357-62.

11. Laskowitz DT, Horsburgh K, Roses AD. Apolipoprotein E and the CNS response to injury. J Cereb Blood Flow Metab. 1998;18:465-71.

12. McCarron MO, Muir KW, Weir CJ, Dyker AG, Bone I, Nicoll JAR, et al. The Apolipoprotein E $\epsilon 4$ allele and outcome in cerebrovascular disease. Stroke. 1998;29:1882-7.

13. Freidman G, Froom P, Sazbon L, Grinblatt I, Shochina M, Tsenter J, et al. Apolipoprotein E $\epsilon 4$ genotype predicts a poor outcome in survivors of traumatic brain injury. Neurology. 1999;52:244-8.

14. Schiefermeier M, Kollegger H, Madi C, Schwarz C, Holzer M, Kofler $\mathrm{J}$, et al. Apolipoprotein E polymorphism survival and neurological outcome after cardiopulmonary resuscitation. Stroke. 2000;31:206873.

15. Chowdhury AH, Yokoyama T, Kokubo Y, Zaman MM, Haque A, Tanaka H. Apolipoprotein E genetic polymorphism and stroke subtypes in a Bangladeshi hospital-based study. J Epidemiol. 2001;11: $131-8$.

16. McCarron MO, Nicoll JAR, Stewart J, Ironside JW, Mann D, Love S, et al. The Apolipoprotein E $\epsilon 4$ allele and the pathological features in cerebral amyloid angiopathy-related hemorrhage. J Neuropathol Exp Neurol. 1999;58:711-8.

17. McCarron M, Delong D, Alberts MJ. APOE genotype as a risk factor for ischemic cerebrovascular disease. Neurology. 1999;53:1308-11.

18. Tardiff E, Newman MF, Saunders AM, Strittmeyer WJ, Blumenthal JA, White WD, et al. Preliminary report of a genetic basis for cognitive decline after cardiac operations. Ann Thorac Surg. 1997;64:715-20.

19. Steed L, Kong R, Stygall J, Acharya J, Bolla M, Harrison MJ, et al. The role of apolipoprotein $\mathrm{E}$ in cognitive decline after cardiac operation. Ann Thorac Surg. 2001;71:823-6.

20. Robson MJA, Alston RP, Andrews PJD, Wehham PR, Souter MJ, Deary IJ. Apolipoprotein E and neurocognitive outcome from coronary artery surgery. J Neurol Neurosurg Psychiatry. 2002;72:675-6.
21. Hixson JE, Vernier DT. Restriction isotyping of human apolipoprotein E by gene amplification and cleavage with Hha 1. J Lipid Res. 1990;31:545-8.

22. Clancy RR, McGaurn SA, Wernovsky G, Spray TL, Norwood WI, Jacobs ML, et al. Preoperative risk-of-death prediction model in heart surgery with deep hypothermic circulatory arrest in the neonate. J Thorac Cardiovasc Surg. 2000;119:347-57.

23. Sing CF, Davigon J. Role of the apolipoprotein E polymorphism in determining normal plasma lipid and lipoprotein variation. Am J Hum Genet. 1985;37:268-85.

24. Eto M, Watanabe K, Ishii K. A racial difference in apolipoprotein E allele frequencies between the Japanese and Caucasian populations. Clin Genet. 1986;30:422-7.

25. Uterman G. Apolipoprotein E polymorphism in health and disease. Am Heart J. 1987;113:433-40.

26. Hallman DM, Boerwinkle E, Saha N, Sandholzer C, Menzel HJ, Csazar A, et al. The apolipoprotein E polymorphism: a comparison of allele frequencies and effects in nine populations. Am J Hum Genet. 1991;49:338-49.

27. Evans AE, Zhang W, Moreel JF, Bard JM, Ricard S, Poirier O, et al. Polymorphisms of the apolipoprotein $\mathrm{B}$ and $\mathrm{E}$ genes and their relationship to plasma lipid variables in healthy Chinese men. Hum Genet. 1993;92:191-7.

28. Methia N, Andre P, Hafezi-Moghadam A, Economopoulos M, Thomas $\mathrm{KL}$, Wagner DD. ApoE deficiency compromises the blood brain barrier especially after injury. Mol Med. 2001;12:810-5.

29. Grocott HP, Newman MF, El-Moalem H, Bainbridge D, Butler A, Laskowitz DT, et al. Apolipoprotein E genotype differentially influences the proinflammatory and anti-inflammatory response to cardiopulmonary bypass. J Thorac Cardiovasc Surg. 2001;122:622-3.

30. Kitagawa K, Matsumoto M, Kuwabara K, Takasawa KI, Tanaka S, Sasaki T, et al. Protective effect of apolipoprotein $\mathrm{E}$ against ischemic neuronal injury is mediated through antioxidant action. J Neurosci Res. 2002;68:226-32.

31. Drabe N, Zund G, Grünenfelder J, Sprenger M, Hoerstrup SP, Bestmann L, et al. Genetic predisposition in patients undergoing cardiopulmonary bypass is associated with an increase of inflammatory cytokines. Eur J Cardiothorac Surg. 2001;20:609-13.

32. Chew STH, Newman MF, White WD, Conlon PJ, Saunders AM, Strittmatter WJ, et al. Preliminary report on the association of apolipoprotein E polymorphisms, with postoperative peak serum creatinine concentrations in cardiac surgical patients. Anesthesiology. 2000;93: 325-31.

33. Nickerson DA, Taylor SL, Fullerton SM, Weiss KM, Clark AG, Steengard JH, et al. Sequence diversity and large-scale typing of SNPs in the human apolipoprotein E gene. Genome Res. 2000;10:1532-45. 